\title{
Estimation of regional gas and tissue volumes of the lung in supine man using computed tomography
}

\author{
D M DENISON, M D L MORGAN, A B MILLAR
}

From the Lung Function and Computed Tomography Units, Brompton Hospital, London

\begin{abstract}
This study was intended to discover how well computed tomography could recover the volume and weight of lung like foams in a body like shell, and then how well it could recover the volume and weight of the lungs in supine man. Model thoraces were made with various loaves of bread submerged in water. Computed tomography scans recovered the volume of the model lungs (true volume range 250-12500 ml) within +0.2 (SD 68) $\mathrm{ml}$ and their weights (true range 72-3125 g) within $+30(78) \mathrm{g}$. Scans also recovered successive injections of $50 \mathrm{ml}$ of water, within $\pm 5 \mathrm{ml}$. Scans in 12 healthy supine men recovered their vital capacities, total lung capacities (TLC), and predicted tissue volumes with comparable accuracy. At total lung capacity the mean tissue volume of single lungs was $431(64) \mathrm{ml}$ and at residual volume (RV) it was $427(63) \mathrm{ml}$. Tissue volume was then used to match inspiratory and expiratory slices and calculate regional ventilation. Throughout the mid $90 \%$ of lung the RV/TLC ratio was fairly constant-mean $21 \%(5 \%)$. New methods of presenting such regional data graphically and automatically are also described.
\end{abstract}

This paper describes a study of estimates of regional gas and tissue volumes in the lungs of healthy people based on computed tomography. A conventional posteroanterior radiograph is an image generated by $x$ rays travelling in straight lines. Its magnification is accurate and determined by simple geometry, from which the size of the lungs can be calculated reliably. ${ }^{1-3}$ The density information it contains, however, condenses three dimensions into two and cannot be used to calculate lung mass. By contrast, a computed tomograph purports to be an accurate map of position and density. It is, however, a fabricated image whose reconstruction rests on several assumptions, which make it vulnerable to error, particularly in the lung.

The primary information for the tomograph is collected in the form of banks of numerical data, describing the $x$ ray intensities falling on each of very many minute sensors as a function of time. Each sensor is read every several milliseconds for a few seconds. Firstly, this information is scanned for, and filtered from, "obvious noise." Secondly, it is corrected for the phenomenon of beam hardening (the absorption of rays of lower energy by radiodense material). This will be especially complex where there

Address for reprint requests: Professor DM Denison, Brompton Hospital, London SW3 6HP.

Accepted 21 January 1986 are steep radiodensity gradients, as in the thorax. Thirdly, the image is reconstructed by effectively throwing back and overlaying the assumed densities of a vast number of single beams (back projection).

Some workers have foreseen that if the computed image is correct it offers accurate estimates of regional gas and tissue volumes in the lung. ${ }^{4}$ Other investigators have shown that the technique provides good estimates of solid organ volume and mass in the abdomen (and in one pulmonary nodule). ${ }^{56} \mathrm{We}$ cannot, however, directly transfer these findings to the lung. Its foam like structure and the complications of cardiac and respiratory motion introduce many artefacts, even in the thinnest and most rapid tomographic sections $(1-3 \mathrm{~mm}, 1-5 \mathrm{~s})$. These occur whenever a volume of space under study is partly occupied, or is occupied part of the time, by an alien tissue. The computed tomography density measured will then be the time and space weighted mean of all the tissue that occupied the volume element (voxel) during the measurement time. These artefacts, known as partial volume effects, are particularly common in the lung, especially at highly curved boundaries at the apices and costophrenic angles.

In the present study we aimed to discover how well computed tomography could recover the volume and weight of lung like foams in a body like shell, and then to find how well it could recover the volume and weight of the lungs in man. 


\section{Methods}

All studies were performed with an Elscint Exel 2002 whole body scanner with a single slice scan time of five seconds. It is a translate-rotate device, which acquires information from a bank of $2901 \times 10 \mathrm{~mm}$ sensors set on an arc of $1.3 \mathrm{~m}$ radius from an $x$ ray source. The arc source boom rotates and then translates at each of five positions during a single scan. In the studies described here the slice interval was varied between 10 and $20 \mathrm{~mm}$, but the slice width was held constant at $10 \mathrm{~mm}$. The tomograph table could be advanced in steps of $1 \mathrm{~mm}$. Preliminary studies showed that table position could be specified and read with an accuracy of $\pm 0.5 \mathrm{~mm}$. Data from the scanner were stored on magnetic tape, and transferred to a separate viewing console for analysis. All measurements were made from screen images and from the digital data banks on magnetic tape, and not from hard copy.

\section{STUDIES ON LUNG LIKE FOAMS}

We needed stable foams, of various densities comparable with healthy and diseased lungs, which could be surrounded by a body like shell (for beam hardening), to model thoraces ranging from that of a small child to that of an emphysematous adult. After some unsuccessful studies with natural sponges and plastic foams that were too radiolucent, we chose loaves of bread, wrapped in polythene film, submerged in a rather bigger bowl of water. The densities varied from 0.174 to 0.465 . In principle, dry French bread approached the density of emphysematous lung and moist pumpernickel bread that of fibrotic lung, with a large range of reproducible doughs between them. Pieces of bread can be packed into any form and volume. We made many such models with volumes ranging from 210 to $16600 \mathrm{ml}$. Their actual volumes were determined by water displacement to the same depth as in the bowl. Their real weights were measured with a gravimetric balance known to be accurate to $\pm 1 \mathrm{~g}$. Because the loaves were more buoyant than the water in which they were submerged they had to be restrained by a lightly weighted rigid plastic sheet above them. They were scanned in pairs, at $1 \mathrm{~cm}$ slice intervals producing images that had several of the qualities of true thoracic scans (fig 1).

The area of each "slice" of bread was calculated by using the arbitrary region of interest subroutine that is built into the manufacturer's software for the console. In this subroutine the operator sketches the boundary of the area of interest, using a joystick control. When the boundary is closed, the subroutine calculates the area it contains. It also takes note of the radiographic density of each contained pixel (in Hounsfield units) and compiles their means and standard deviations.

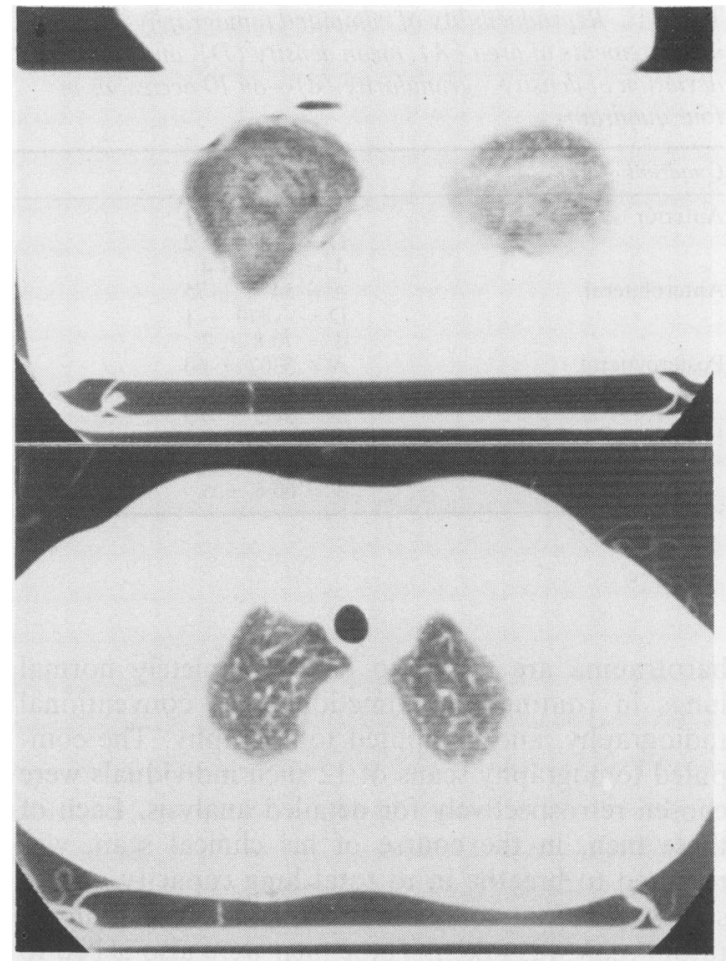

Fig 1 Computed tomography scan of a model thorax, showing two loaves wrapped in polythene film and submerged below water (above), compared with one scan of the thorax in a healthy man (below).

We calculated the product of slice area and slice interval to obtain a computed tomography estimate of slice volume, and the product of slice volume and mean slice density to obtain a computed tomography estimate of slice mass (that is, tissue volume). To do this we assumed a linear relation between physical density and Hounsfield number in the range 0 (= water) to $-1000(=$ air $)$. The estimated volumes and weights of all the "slices" were summed to obtain computed tomography estimates of the volume and weight of each loaf.

To assess the reproducibility of the arbitrary region of interest subroutine, we took a typical computed tomography scan of one slice of a normal subject's right lung, divided it into anterior, anterolateral, posterolateral, and posterior quadrants and estimated the area, density, and granularity (standard deviation of density) of each quadrant on 10 occasions, obtaining the results summarised in table 1 . Area is reproduced within $\pm 2 \%$, density within $\pm 2 \%$, and granularity within $\pm 8 \%$.

STUDIES OF LUNGS IN MAN

Some commercial divers referred to us with suspected 
Table 1 Reproducibility of computed tomography measurements of area $(A)$, mean density $(D)$, and standard deviation of density - granularity $(d)$-on 10 occasions in four quadrants

\begin{tabular}{ll}
\hline Quadrant & Results \\
\hline Anterior & $\mathrm{A}=2411 \pm 41$ \\
& $\mathrm{D}=-873 \pm 2$ \\
Anterolateral & $\mathrm{d}=57 \cdot 7 \pm 4$ \\
& $\mathrm{~A}=5475 \pm 75$ \\
Posterolateral & $\mathrm{D}=-879 \pm 1$ \\
& $\mathrm{~d}=70 \cdot 8 \pm 2$ \\
Posterior & $\mathrm{A}=5307 \pm 60$ \\
& $\mathrm{D}=-852 \pm 1$ \\
& $\mathrm{~d}=84 \cdot 5 \pm 0 \cdot 5$ \\
& $\mathrm{~A}=1725 \pm 34$ \\
& $\mathrm{D}=-834 \pm 2$ \\
& $\mathrm{~d}=60 \cdot 6 \pm 5$ \\
\hline
\end{tabular}

barotrauma are found to have completely normal lungs in routine lung function tests, conventional radiography, and computed tomography. The computed tomography scans of 12 such individuals were chosen retrospectively for detailed analysis. Each of these men, in the course of his clinical scan, was required to breathe in to total lung capacity and to signal when that volume was reached before an inspiratory scan was taken. These men were also asked to breathe out to residual volume, and signal when that volume was reached before an expiratory view was recorded. Their lungs were examined in this fashion from apex to base, at total lung capacity and again at residual volume, at slice intervals that varied from 10 to $20 \mathrm{~mm}$.

These scans were viewed at the console, the organ identification subroutine built into the manufacturer's software being used. In this routine the upper and lower limits of densities to be included are specified by the operator, who also indicates a point within the organ in question. The routine then automatically draws the outline containing all the confluent pixels having densities within the given range. It then assesses the area and the mean density and granularity of the region so outlined. To assess the reproducibility of this subroutine we applied it to two typical slices of a normal thorax, on 10 occasions each. Identical values of area, mean density, and granularity were obtained on every occasion.

The density boundary we chose was -300 Hounsfield units, (HU). In inspiration normal lung tissue has an average density of $-870 \mathrm{HU}$, and in expiration of about $-670 \mathrm{HU}$. Soft tissues like the heart, blood vessels, and inner lining of the chest wall have average densities of about $+40 \mathrm{HU}$. In this study voxel sizes were about $1 \times 1 \times 10 \mathrm{~mm}$. The boundary we chose would automatically reject any voxel containing more than $17 \%$ non-lung soft tissue,
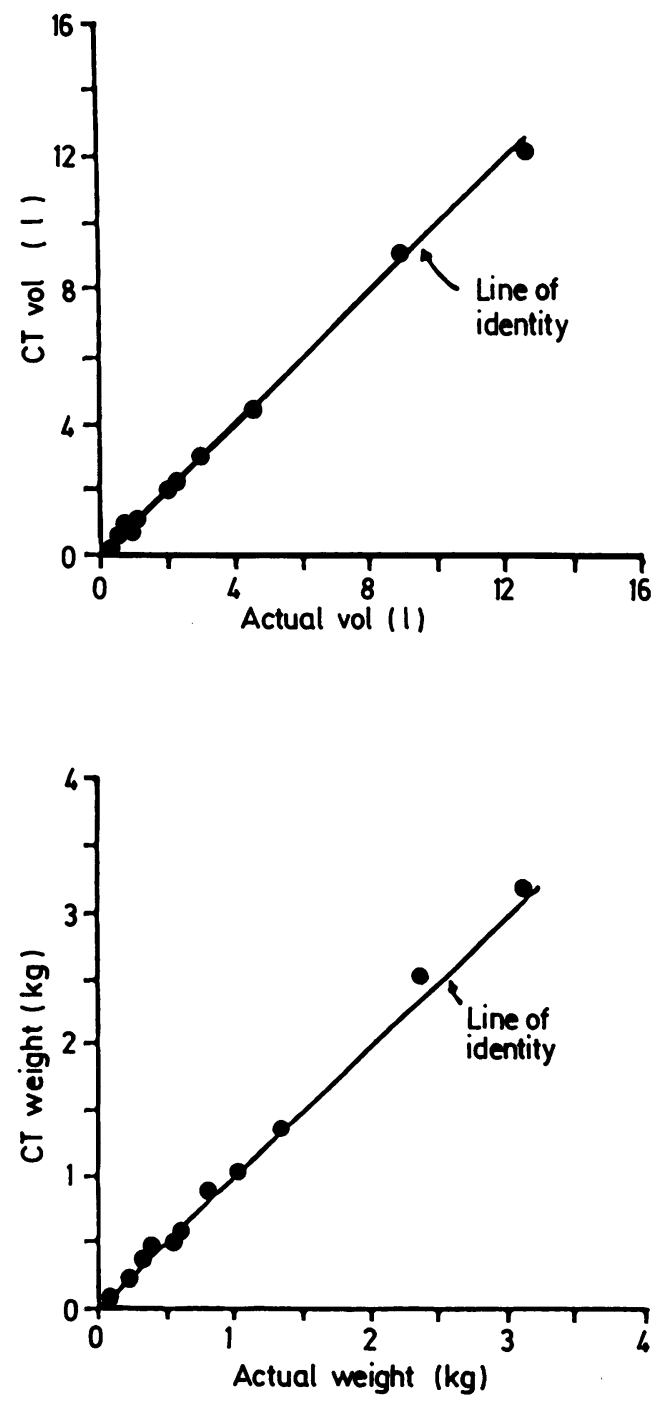

Fig 2 Comparison of computed tomography (CT) and water displacement estimates of model lung volumes (above) and of computed tomography and gravimetric estimates of model lung weights (below). The average error in the volume estimate was +0.2 (SD 68) $\mathrm{ml}$; the average error in the weight estimate was +30 (78) $\mathrm{g}$.

equivalent in the long axis of the voxel to a depth of $1.7 \mathrm{~mm}$. Within the lung it would exclude any voxel containing a vessel of that width. Vessels are, however, unlikely to be aligned within voxel borders and they are circular in cross section. Allowing for these facts we think that a diameter of $5 \mathrm{~mm}$ is a more realistic threshold for exclusion of vessels. 
Estimation of regional gas and tissue volumes of the lung in supine man using computed tomography

Table 2 A comparison of computed tomography (CT) and water displacement estimates of volume, and of computed tomography and gravimetric estimates of weight in 11 model lungs

\begin{tabular}{|c|c|c|c|c|c|c|}
\hline \multirow[b]{2}{*}{ Model } & \multicolumn{2}{|c|}{ Volume ( $\mathrm{ml})$} & \multicolumn{2}{|c|}{ Weight $(g)$} & \multicolumn{2}{|c|}{ Density $(\mathrm{g} / \mathrm{ml})$} \\
\hline & Real & $C T$ & Real & $C T$ & Real & $C T$ \\
\hline $\begin{array}{r}1 \\
2 \\
3 \\
4 \\
5 \\
6 \\
7 \\
8 \\
9 \\
10 \\
11\end{array}$ & $\begin{array}{r}209 \\
1120 \\
1160 \\
1162 \\
1170 \\
2085 \\
2180 \\
2875 \\
4520 \\
8950 \\
12500\end{array}$ & $\begin{array}{r}175 \\
1118 \\
1201 \\
1132 \\
1166 \\
2070 \\
2176 \\
2947 \\
4528 \\
9045 \\
12375\end{array}$ & $\begin{array}{r}72 \\
508 \\
371 \\
202 \\
336 \\
596 \\
1013 \\
816 \\
1334 \\
2360 \\
3125\end{array}$ & $\begin{array}{r}67 \\
452 \\
398 \\
227 \\
345 \\
568 \\
1012 \\
855 \\
1352 \\
2555 \\
3231\end{array}$ & $\begin{array}{l}0.344 \\
0.454 \\
0.320 \\
0.174 \\
0.287 \\
0.286 \\
0.465 \\
0.284 \\
0.295 \\
0.264 \\
0.254\end{array}$ & $\begin{array}{l}0.383 \\
0.404 \\
0.331 \\
0.154 \\
0.246 \\
0.274 \\
0.465 \\
0.290 \\
0.299 \\
0.282 \\
0.267\end{array}$ \\
\hline
\end{tabular}

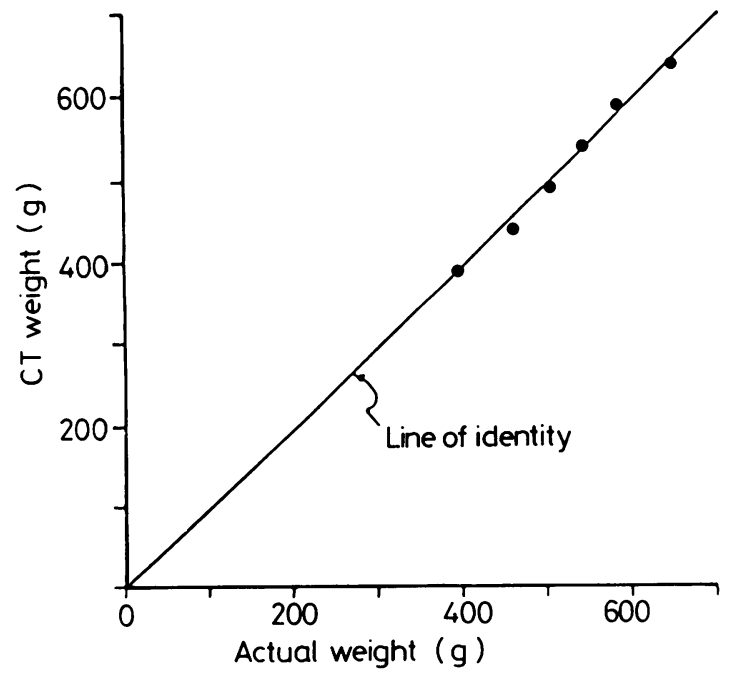

Fig 3 Comparison of computed tomography (CT) and gravimetric estimates of the weight of a model lung before and after the injection of each of five $50 \mathrm{ml}$ aliquots of water (weight changes agreeing within $\pm 5 \mathrm{~g}$ ).

\section{Results}

MODEL LUNGS

The actual weights and volumes of 11 bread models of lung and those estimated by computed tomography are summarised in table 2 and figure 2 . The average error in the volume estimate was +0.2 (SD $68) \mathrm{ml}$ in the volume range $210-12500 \mathrm{ml}$. The average error in the weight estimate was $+30(78) \mathrm{g}$ in the weight range $72-3125 \mathrm{~g}$.

To discover whether the computed tomography technique could sense small changes in fluid volume within a lung like foam surrounded by a body like shell, we conducted the subsidiary experiment summarised in figure 3-that is, we injected five aliquots of $50 \mathrm{ml}$ of water into a loaf, initially weighing $385 \mathrm{~g}$, and rescanned it after each injection to recover the weight and added fluid within $\pm 5 \mathrm{ml}$, as shown in the figure.

\section{HUMAN LUNGS}

Details of the age, build, and routine lung function

Table 3 Details of normal subjects studied

\begin{tabular}{|c|c|c|c|c|c|c|c|c|}
\hline \multirow{2}{*}{$\begin{array}{l}\text { Subject } \\
\text { No } \\
\end{array}$} & \multirow[b]{2}{*}{$\begin{array}{l}\text { Age } \\
(y)\end{array}$} & \multirow{2}{*}{$\begin{array}{l}\text { Height } \\
(\mathrm{cm})\end{array}$} & \multicolumn{6}{|c|}{ Lung function ( $\%$ predicted) } \\
\hline & & & $F E V_{1}$ & $F V C$ & $T L C$ & $R V$ & $T L C O$ & $\mathrm{KCO}$ \\
\hline $\begin{array}{l}1 \\
2 \\
3 \\
4 \\
5 \\
6 \\
7 \\
8 \\
9 \\
10 \\
11 \\
12 \\
\text { Mean } \\
\text { SD }\end{array}$ & $\begin{array}{l}17 \\
21 \\
26 \\
28 \\
32 \\
32 \\
34 \\
35 \\
41 \\
42 \\
48 \\
52 \\
34 \\
10 \cdot 4\end{array}$ & $\begin{array}{c}183 \\
169 \\
185 \\
168 \\
181 \\
174 \\
175 \\
193 \\
182 \\
163 \\
174 \\
176 \\
177 \\
8.3\end{array}$ & $\begin{array}{c}93 \\
108 \\
101 \\
94 \\
97 \\
114 \\
101 \\
110 \\
98 \\
107 \\
109 \\
93 \\
103 \cdot 3 \\
7 \cdot 5\end{array}$ & $\begin{array}{c}84 \\
115 \\
105 \\
65 \\
98 \\
93 \\
103 \\
115 \\
114 \\
112 \\
97 \\
105 \\
100 \cdot 5 \\
14 \cdot 7\end{array}$ & $\begin{array}{c}107 \\
89 \\
91 \\
99 \\
95 \\
117 \\
98 \\
92 \\
83 \\
96 \\
111 \\
85 \\
96 \cdot 9 \\
10 \cdot 3\end{array}$ & $\begin{array}{c}95 \\
94 \\
119 \\
85 \\
104 \\
135 \\
102 \\
79 \\
132 \\
112 \\
136 \\
128 \\
110 \\
19.9\end{array}$ & $\begin{array}{r}91 \\
118 \\
103 \\
115 \\
94 \\
109 \\
122 \\
81 \\
110 \\
122 \\
108 \\
96 \\
106 \\
13\end{array}$ & $\begin{array}{c}103 \\
105 \\
97 \\
124 \\
91 \\
116 \\
119 \\
75 \\
101 \\
113 \\
121 \\
95 \\
105 \\
14.4\end{array}$ \\
\hline
\end{tabular}

FVC-forced vital capacity; TLC—-total lung capacity; RV—residual volume; TLco-transfer factor for carbon monoxide; Kco-transfer coefficient. 


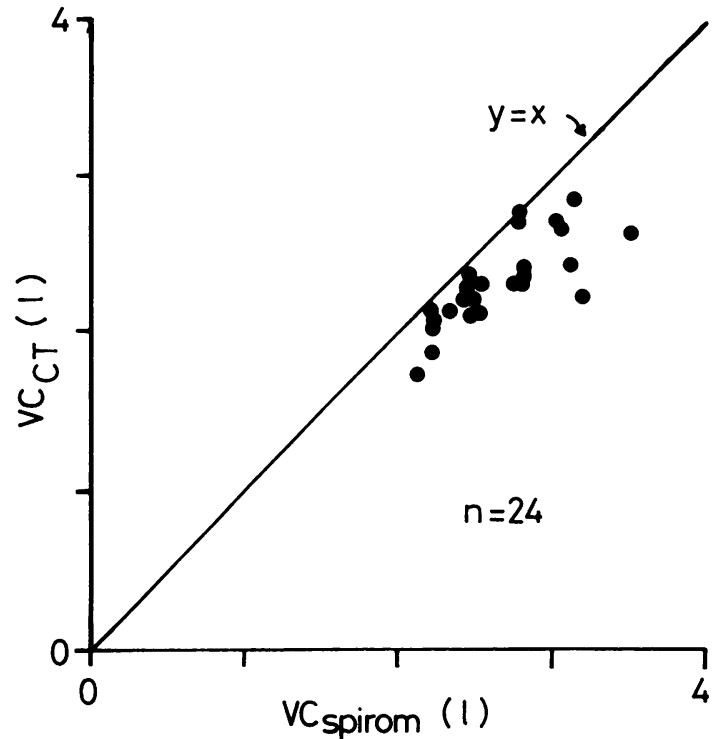

Fig 4 Comparison of computed tomography (CT) and spirometric estimates of single lung vital capacity (VC) in 12 healthy men; in each case $47.5 \%$ of the spirometric measure of whole lung vital capacity was apportioned to the left lung and the remainder to the right lung. ${ }^{8} \mathrm{VC} \mathrm{Cr}_{\mathrm{CT}}=$ $89.6 \%$ (SD 5.9\%) $V C_{\text {spirom; the mean }}(S D)$ error in $V C_{C T}$ was $301(178) \mathrm{ml}$. $V C_{\mathrm{CT}}=95.6 \%(6.3 \%) V C_{\text {spirom }}$ corrected for the known reduction of $V C$ in the supine position. ${ }^{9}$

characteristics of the 12 men studied are given in table 3. The predictions for normality used in the table are based on those of Cotes, ${ }^{7}$ modified by a recent study in our laboratory on 165 healthy people aged 30-60 years (unpublished observations).

The computed tomography estimates of lung volumes were compared with spirometric measurements of vital capacity and the whole body plethysmographic estimates of total lung capacity (figs 4 and 5). Computed tomography estimates of vital capacity were calculated from the differences in pulmonary gas volume at total lung capacity and residual volume, and not simply from differences in lung volume. They therefore demonstrate the ability of computed tomography to measure changes in gaseous volume. The computed tomography estimates of lung weight were compared with the product of Weibel's estimate of peripheral lung density at total lung capacity ${ }^{11}$ and the subject's plethysmographic lung volume (fig 6). This study showed that there was close agreement between the tissue volumes of the 24 right or left lungs at total lung capacity and residual volume (fig 7). At total lung capacity the tissue volumes of single lungs were $431 \pm 64 \mathrm{ml}$. At residual volume they were $427 \pm 63 \mathrm{ml}$.

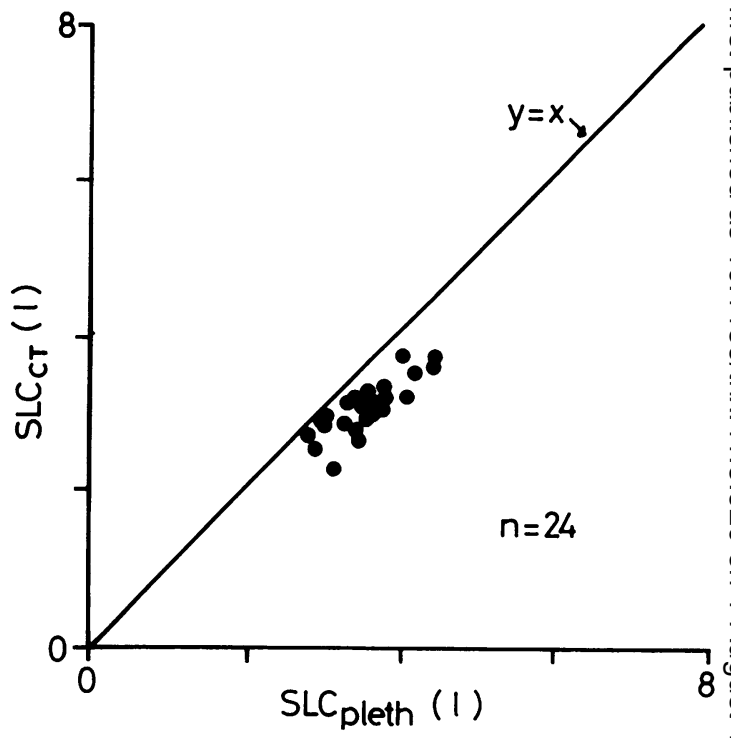

Fig 5 Comparison of CT and whole body plethysmographic estimates of single lung capacity (SLC) in 12 healthy men. In each case $47.5 \%$ of the plethysmographic measure of total lung capacity was apportioned to the left lung, and the remainder to the right lung. ${ }^{8} S L C_{\mathrm{CT}}=84 \cdot 8 \%(S D 5 \cdot 8 \%)$ $S L C_{\text {pleth; the mean }}(S D)$ error in SLC CT was 551 (249) $\mathrm{ml}$. $S L C_{\mathrm{CT}}=91.8 \%(S D 6.3 \%) S L C_{\text {pleth }}$ corrected for the known reduction in total lung capacity in the supine posture. ${ }^{10}$

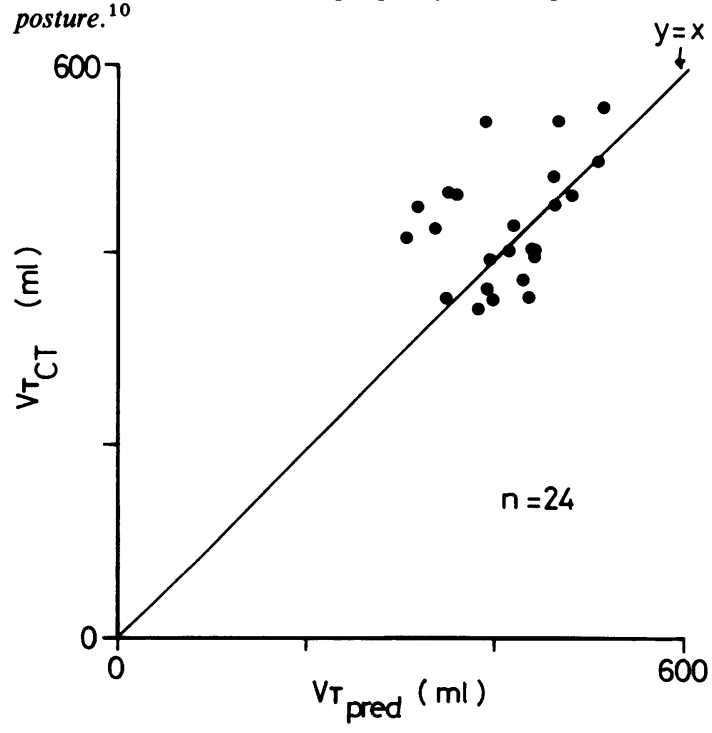

Fig 6 Comparison of computed tomography (CT) estimates and whole body plethysmographic predictions of single lung tissue volume (VT) in 12 healthy men. In each case $47.5 \%$ of the plethysmographic measure of total lung capacity (TLC) was apportioned to the left lung and the remainder to the right. These volumes were then multiplied by Weibel's ${ }^{11}$ estimate of lung density at TLC $(0 \cdot 114)$ to obtain the plethysmographic prediction of single lung tissue volume $\left(V T_{\text {pred }}\right) . V T_{\mathrm{CT}}=106 \%(S D 18 \cdot 3 \%) V T_{\text {pred }}$; the mean (SD) error in $V T_{\mathrm{CT}}$ was $-32(71) \mathrm{ml}$. 


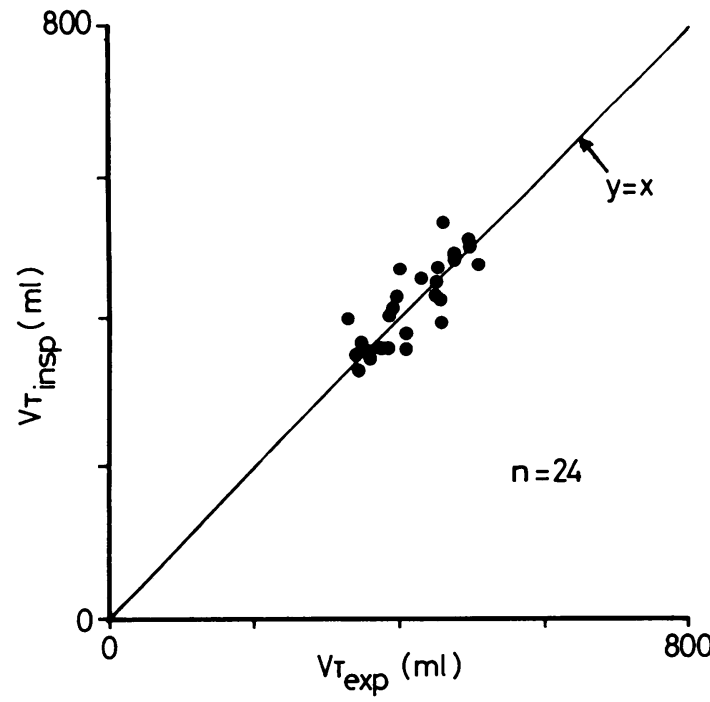

Fig 7 Comparison of computed tomography (CT) estimates of single lung tissue volume at total lung capacity $\left(V T_{\text {insp }}\right)$ and at residual volume ( $\left.V T_{\text {exp }}\right)$ in 12 healthy men. $V T_{\text {insp }}=102 \%(S D 7.7 \%) V T_{\text {pred; }}$, the mean $(S D)$ error in $V T_{\text {insp }}$ was $+10(38) \mathrm{ml}$.

\section{ANALYTIC TREATMENT OF THE RESULTS}

At this stage in the analysis of the results it was clear from the studies on bread that computed tomography could produce good estimates of the volume and

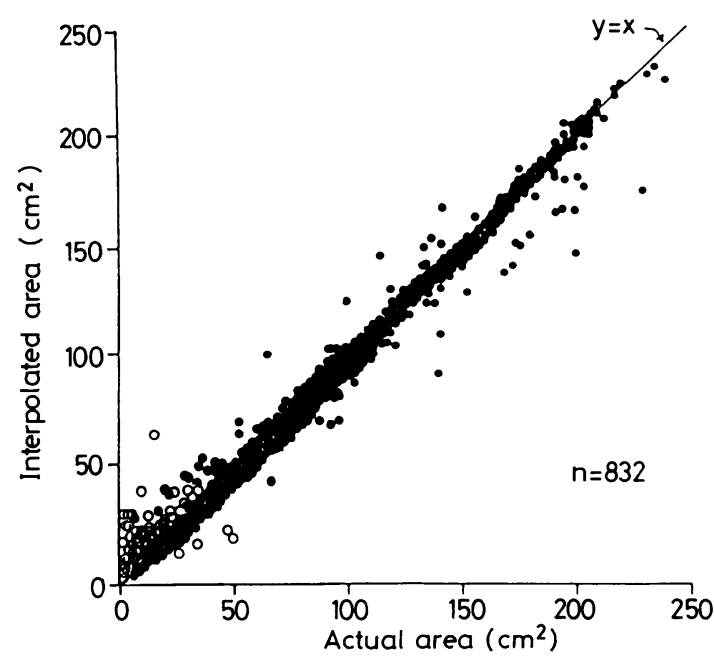

Fig 8 Comparison of actual and interpolated estimates of the area of 832 computed tomography slices of single lungs in 12 healthy men. Open circles indicate slices, of very small volume, at the extreme apex or base of the lung; closed circles indicate slices in the middle $95 \%$ of the lung. In practice, departures from the line of identity will on average be four times less than those shown here. weight of lung-like foams in a body-like shell, and could also detect minor variations in water content with an apparent resolution of $\pm 5 \mathrm{ml}$. The human studies suggested it could produce credible estimates of lung volume and weight in man. They also indicated that tissue volume was very similar at total lung capacity and residual volume.

The conservation of tissue volume from total lung capacity to residual volume suggested the possibility of using it as a marker to identify matching slices of lung in inspiratory and expiratory scans, so that regional vital capacities and residual volume could be calculated.

The principle of the method of matching would be to accumulate the total tissue volume of the single lungs, from apex to base, this accumulating total being used as a marker to identify corresponding levels at the two extremes of the respiratory cycle. Since the matching level at one extreme would often lie somewhere between the neighbouring slices that were actually taken, the properties of mythical intermediate slices would have to be interpolated. This assumes that the distribution of slice area and mass is continuous, in a fashion that permits interpolation. To check this, we could have scanned the subjects at many intermediate levels and compared the interpolated and measured values. This, however, would have required additional radiation exposure, for no clinical gain, which was unacceptable.

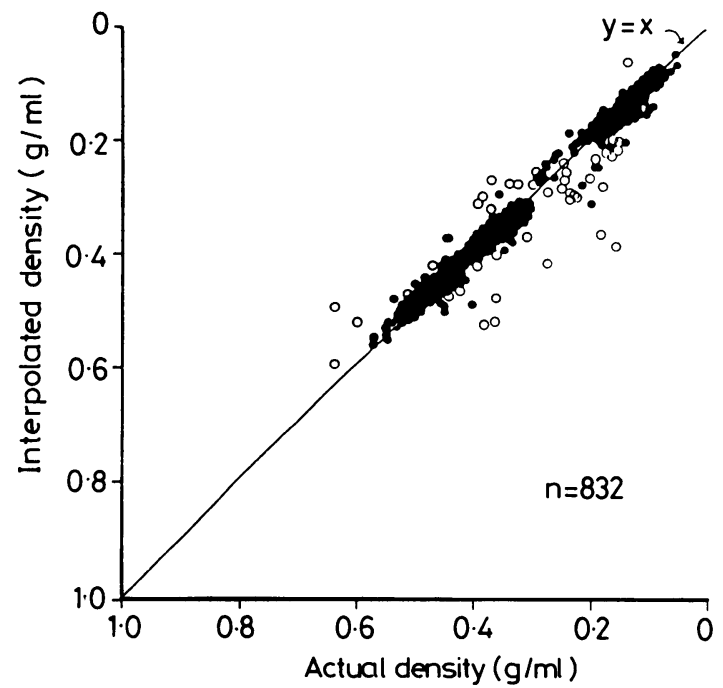

Fig 9 Comparison of actual and interpolated estimates of the density of 832 computed tomography slices of single lungs of 12 healthy men. Open circles indicate slices, of very small volume, at the extreme apex or base of the lung; closed circles indicate slices in the middle $95 \%$ of the lung. In practice, departures from the line of identity will on average be four times less than those shown here. 

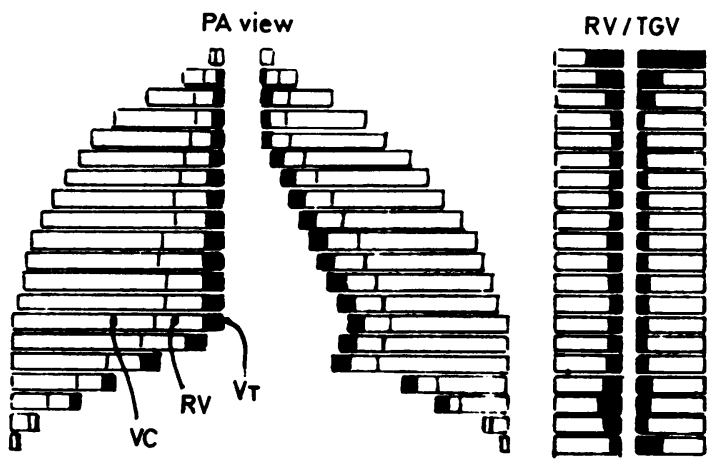

We chose to test the power of interpolation over the wider range between alternate slices that were actually taken - for example, using slices 3 and 5 to predict the properties of slice 4 , which was actually taken, and so on. This procedure would, on average, mean jumps of four times the average jump between neighbouring slices. Thus the observed error would be four times as great as the average error likely to be seen with existing slices. The results of these comparisons are presented in figures 8 and 9 , which show that slice area can be interpolated from alternate slices with a random error of $\pm 5 \mathrm{~cm}^{2}$ and that slice density can be interpolated from alternate slices with a random error of \pm 0.03 . Dividing these errors by four to get the expected error when intermediate slices are predicted from neighbouring areas gives errors of $\pm 1.3 \mathrm{~cm}^{2}$ and \pm 0.01 respectively. Figure 9 shows that in healthy supine lungs density is continuously distributed from the apex to the base, and suggests a basis for quantifying irregularities of distribution.

This finding suggested that it was reasonable to

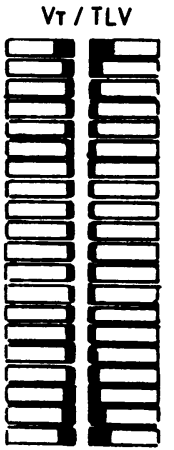

Fig 10 Graphical presentation of regional information obtained from computed tomography scans at total lung capacity and residual volume in one 48 year old healthy man. The diagram on the left summarises, for each slice of lung, local tissue volume (VT), shown by the shaded bar; residual volume $(R V)$, shown by the smaller unshaded bar; total gas volume (TGV), shown by the combined length of the two unshaded bars; and total lung volume (TLV), shown by the combined length of all three bars. These characteristics are shown as proportions of total TGV or TLV in the two sets of bar charts on the right. PA-posteroanterior.

match inspiratory and expiratory scans in this way, which, in turn, implied that we could calculate regional total lung and gas volumes, vital capacities, and residual volumes by simple subtraction. We could also calculate regional tissue volumes directly. Clearly, this would generate a series of numbers for each lung, which would be difficult to comprehend directly. To overcome this we chose to present the data in the graphical form shown in figure 10. The left hand part of the figure shows a bar chart of the properties of the right and left lung, in a form that is easily recognisable and can, if necessary, be directly laid over a conventional posteroanterior radiograph of the lung. The rectangular bar charts on the right of the figure summarise the lung properties in a way that allows functions of different regions to be compared directly.

Table 4 shows values for regional tissue volume in all 12 normal subjects. At the very top and bottom of the lung there are some discrepancies, because partial volume effects are considerable in these highly curved

Table 4 Values of tissue volume/total volume (\%) at total lung capacity in serial "slices" of the right (R) and left (L) lungs of 12 healthy을 men (values shown for the mid $90 \%$ of the lung from the 5th to 95 th percentile of apex to base tissue content)

\begin{tabular}{|c|c|c|c|c|c|c|c|c|c|c|c|c|c|c|c|c|c|c|c|c|c|c|c|c|c|}
\hline \multirow{3}{*}{$\begin{array}{l}\text { "Slice" \% of } \\
\text { distances shown } \\
\text { lung }\end{array}$} & \multicolumn{24}{|c|}{ Subject No } & \multirow{3}{*}{$\begin{array}{l}\text { Mean (SD), } \\
\text { each "slice" }\end{array}$} \\
\hline & \multicolumn{2}{|l|}{$\overline{1}$} & \multicolumn{2}{|l|}{2} & \multicolumn{2}{|l|}{3} & \multicolumn{2}{|l|}{4} & \multicolumn{2}{|l|}{5} & \multicolumn{2}{|l|}{6} & \multicolumn{2}{|l|}{7} & \multicolumn{2}{|l|}{8} & \multicolumn{2}{|l|}{9} & \multicolumn{2}{|l|}{10} & \multicolumn{2}{|l|}{11} & \multicolumn{2}{|l|}{12} & \\
\hline & $R$ & $L$ & $R$ & $L$ & $R$ & $L$ & $R$ & $L$ & $R$ & $L$ & $R$ & $L$ & $R$ & $L$ & $R$ & $L$ & $R$ & $L$ & $R$ & $L$ & $R$ & $L$ & $R$ & $L$ & \\
\hline $\begin{array}{l}5-15 \\
15-25 \\
25-35 \\
35-45 \\
45-55 \\
55-65 \\
65-75 \\
75-85 \\
85-95 \\
\text { Mean }\end{array}$ & $\begin{array}{l}20 \\
14 \\
14 \\
14 \\
15 \\
14 \\
14 \\
14 \\
27 \\
16\end{array}$ & $\begin{array}{l}19 \\
14 \\
14 \\
14 \\
15 \\
14 \\
14 \\
13 \\
17 \\
15\end{array}$ & $\begin{array}{r}15 \\
8 \\
10 \\
9 \\
10 \\
12 \\
12 \\
12 \\
20 \\
12\end{array}$ & $\begin{array}{r}14 \\
8 \\
8 \\
9 \\
10 \\
11 \\
12 \\
12 \\
25 \\
12\end{array}$ & $\begin{array}{l}12 \\
16 \\
10 \\
10 \\
11 \\
10 \\
10 \\
13 \\
19 \\
12\end{array}$ & $\begin{array}{r}12 \\
8 \\
10 \\
10 \\
10 \\
12 \\
12 \\
15 \\
26 \\
13\end{array}$ & $\begin{array}{l}20 \\
14 \\
16 \\
12 \\
14 \\
12 \\
12 \\
16 \\
16 \\
22 \\
16\end{array}$ & $\begin{array}{l}20 \\
14 \\
16 \\
14 \\
14 \\
16 \\
16 \\
18 \\
24 \\
17\end{array}$ & $\begin{array}{l}19 \\
10 \\
10 \\
10 \\
10 \\
10 \\
10 \\
14 \\
17 \\
12\end{array}$ & $\begin{array}{l}14 \\
10 \\
10 \\
11 \\
10 \\
12 \\
10 \\
11 \\
18 \\
12\end{array}$ & $\begin{array}{l}20 \\
14 \\
10 \\
12 \\
12 \\
10 \\
10 \\
15 \\
20 \\
14\end{array}$ & $\begin{array}{l}21 \\
14 \\
12 \\
11 \\
12 \\
12 \\
13 \\
15 \\
21 \\
15\end{array}$ & $\begin{array}{r}18 \\
12 \\
12 \\
8 \\
10 \\
10 \\
8 \\
16 \\
22 \\
13\end{array}$ & $\begin{array}{l}24 \\
12 \\
12 \\
10 \\
12 \\
12 \\
12 \\
12 \\
18 \\
14\end{array}$ & $\begin{array}{l}30 \\
13 \\
10 \\
10 \\
12 \\
10 \\
12 \\
15 \\
20 \\
15\end{array}$ & $\begin{array}{l}48 \\
14 \\
12 \\
11 \\
12 \\
12 \\
12 \\
11 \\
20 \\
17\end{array}$ & $\begin{array}{l}20 \\
12 \\
12 \\
12 \\
10 \\
10 \\
12 \\
16 \\
20 \\
14\end{array}$ & $\begin{array}{l}24 \\
12 \\
12 \\
12 \\
12 \\
12 \\
14 \\
24 \\
28 \\
17\end{array}$ & $\begin{array}{l}19 \\
10 \\
11 \\
10 \\
10 \\
10 \\
12 \\
13 \\
12 \\
12\end{array}$ & $\begin{array}{l}19 \\
10 \\
11 \\
10 \\
12 \\
12 \\
10 \\
13 \\
18 \\
13\end{array}$ & $\begin{array}{l}12 \\
14 \\
12 \\
12 \\
12 \\
14 \\
16 \\
17 \\
23 \\
15\end{array}$ & $\begin{array}{l}25 \\
14 \\
12 \\
13 \\
12 \\
15 \\
16 \\
17 \\
21 \\
16\end{array}$ & $\begin{array}{r}26 \\
14 \\
10 \\
10 \\
10 \\
10 \\
9 \\
12 \\
19 \\
13\end{array}$ & $\begin{array}{l}32 \\
14 \\
10 \\
10 \\
10 \\
10 \\
10 \\
14 \\
19 \\
14\end{array}$ & $\begin{array}{l}21(8) \\
12(2) \\
12(2) \\
11(2) \\
12(2) \\
12(2) \\
12(2) \\
15(3) \\
21(4)\end{array}$ \\
\hline $\begin{array}{l}\text { SD for each } \\
\text { subject }\end{array}$ & 4 & 2 & 4 & 5 & 3 & 5 & 3 & 3 & 4 & 3 & 4 & 4 & 5 & 4 & 6 & 12 & 4 & 7 & 3 & 3 & 4 & 4 & 6 & 7 & \\
\hline
\end{tabular}

distances shown

lung 
Estimation of regional gas and tissue volumes of the lung in supine man using computed tomography

Table 5 Values of residual volume/total gas capacity $(\%)$ in serial "slices" of the right $(R)$ and left $(L)$ lungs of 12 healthy men (values shown for the mid $90 \%$ of the lung from the 5 th to 95 th percentile of apex to base tissue content; all values derived from comparison of scans at residual volume and total lung capacity)

\begin{tabular}{|c|c|c|c|c|c|c|c|c|c|c|c|c|c|c|c|c|c|c|c|c|c|c|c|c|c|}
\hline \multirow{3}{*}{$\begin{array}{l}\text { "Slice" \% of } \\
\text { distance down } \\
\text { lung }\end{array}$} & \multicolumn{24}{|c|}{ Subject No } & \multirow{3}{*}{$\begin{array}{l}\text { Mean (SD) for } \\
\text { each "slice" }\end{array}$} \\
\hline & \multicolumn{2}{|l|}{1} & \multicolumn{2}{|l|}{2} & \multicolumn{2}{|l|}{3} & \multicolumn{2}{|l|}{4} & \multicolumn{2}{|l|}{5} & \multicolumn{2}{|l|}{6} & \multicolumn{2}{|l|}{7} & \multicolumn{2}{|l|}{8} & \multicolumn{2}{|l|}{9} & \multicolumn{2}{|l|}{10} & \multicolumn{2}{|l|}{11} & \multicolumn{2}{|l|}{12} & \\
\hline & $R$ & $L$ & $R$ & $L$ & $R$ & $L$ & $R$ & $L$ & $R$ & $L$ & $R$ & $L$ & $R$ & $L$ & $\boldsymbol{R}$ & $L$ & $R$ & $L$ & $R$ & $L$ & $R$ & $L$ & $R$ & $L$ & \\
\hline $\begin{array}{l}5-15 \\
15-25 \\
25-35 \\
35-45 \\
45-55 \\
55-65 \\
65-75 \\
75-85 \\
85-95 \\
\text { Mean } \\
\text { SD for each }\end{array}$ & $\begin{array}{l}28 \\
19 \\
24 \\
26 \\
27 \\
25 \\
28 \\
30 \\
42 \\
28\end{array}$ & $\begin{array}{l}32 \\
16 \\
15 \\
26 \\
18 \\
18 \\
22 \\
22 \\
37 \\
22\end{array}$ & $\begin{array}{r}15 \\
8 \\
10 \\
10 \\
15 \\
12 \\
15 \\
16 \\
25 \\
14\end{array}$ & $\begin{array}{l}23 \\
10 \\
14 \\
13 \\
15 \\
19 \\
18 \\
18 \\
25 \\
17\end{array}$ & $\begin{array}{l}30 \\
20 \\
24 \\
24 \\
25 \\
24 \\
21 \\
24 \\
48 \\
27\end{array}$ & $\begin{array}{l}25 \\
17 \\
18 \\
19 \\
20 \\
19 \\
17 \\
17 \\
24 \\
20\end{array}$ & $\begin{array}{l}38 \\
20 \\
28 \\
26 \\
26 \\
22 \\
24 \\
20 \\
30 \\
26\end{array}$ & $\begin{array}{l}32 \\
16 \\
18 \\
18 \\
18 \\
18 \\
20 \\
22 \\
30 \\
21\end{array}$ & $\begin{array}{l}34 \\
19 \\
22 \\
23 \\
25 \\
26 \\
25 \\
34 \\
40 \\
28\end{array}$ & $\begin{array}{l}39 \\
16 \\
18 \\
19 \\
21 \\
22 \\
21 \\
33 \\
37 \\
25\end{array}$ & $\begin{array}{l}39 \\
18 \\
20 \\
25 \\
24 \\
24 \\
25 \\
28 \\
27 \\
27\end{array}$ & $\begin{array}{l}43 \\
18 \\
18 \\
21 \\
22 \\
22 \\
20 \\
25 \\
28 \\
24\end{array}$ & $\begin{array}{l}36 \\
16 \\
20 \\
16 \\
18 \\
16 \\
10 \\
32 \\
36 \\
23\end{array}$ & $\begin{array}{l}52 \\
16 \\
16 \\
14 \\
18 \\
16 \\
18 \\
28 \\
24 \\
22\end{array}$ & $\begin{array}{l}48 \\
32 \\
28 \\
28 \\
31 \\
30 \\
27 \\
28 \\
29 \\
37\end{array}$ & $\begin{array}{l}68 \\
28 \\
24 \\
26 \\
28 \\
26 \\
26 \\
26 \\
28 \\
31\end{array}$ & $\begin{array}{l}48 \\
26 \\
28 \\
28 \\
24 \\
24 \\
22 \\
28 \\
40 \\
30\end{array}$ & $\begin{array}{l}82 \\
26 \\
28 \\
26 \\
26 \\
24 \\
26 \\
42 \\
40 \\
36\end{array}$ & $\begin{array}{l}50 \\
12 \\
22 \\
23 \\
22 \\
23 \\
24 \\
26 \\
29 \\
26\end{array}$ & $\begin{array}{l}54 \\
17 \\
22 \\
22 \\
25 \\
26 \\
20 \\
23 \\
32 \\
27\end{array}$ & $\begin{array}{l}42 \\
21 \\
19 \\
22 \\
22 \\
25 \\
32 \\
24 \\
25 \\
26\end{array}$ & $\begin{array}{l}90 \\
21 \\
19 \\
20 \\
21 \\
24 \\
26 \\
25 \\
32 \\
31\end{array}$ & $\begin{array}{l}70 \\
32 \\
28 \\
27 \\
32 \\
31 \\
26 \\
28 \\
36 \\
34\end{array}$ & $\begin{array}{l}55 \\
39 \\
26 \\
27 \\
29 \\
26 \\
26 \\
32 \\
25 \\
32\end{array}$ & $\begin{array}{l}47(21) \\
20(7) \\
21(5) \\
22(5) \\
23(5) \\
23(4) \\
23(4) \\
26(6) \\
32(7)\end{array}$ \\
\hline $\begin{array}{l}\text { SD for each } \\
\text { subject }\end{array}$ & 6 & 7 & 5 & 5 & 8 & 3 & 6 & 6 & 7 & 9 & 7 & 8 & 9 & 12 & 23 & 14 & 9 & 19 & 10 & 11 & 7 & 23 & 14 & 10 & \\
\hline
\end{tabular}

but small volumes. In the middle $70 \%$ of lung volume (15-85\% of the distance from apex to base) the distribution of tissue volume is very uniform at about $12 \%$ (SD 2\%) of total lung volume.

Table 5 shows values for regional residual volume as a percentage of total gas capacity (RV/TGC) in all 12 normal subjects. Partial volume effects again disturb the values in the uppermost and lowermost slices, but in the middle $70 \%$ of lung volume the proportion is fairly uniform, with average RV/TGC ratios of about $23 \%(5 \%)$.

\section{Discussion}

This paper rests on the demonstration that computed tomography scans accurately capture the density and volume of lung like foams surrounded by a body like exterior. Other workers have found that there is a linear association, lying close to the line of identity, between computed tomography and direct estimates of density - of plastic materials in the narrow density range 1.00-1.34 and of isolated biological materials in the density range $0 \cdot 92-2 \cdot 20,{ }^{12}$ of plastic foams in the density range 0.01 to $1.00,{ }^{13} 14$ and of isolated baboon lungs. ${ }^{15}$ Others again have strapped pots or tubes of water to the chest in man, to provide explicit evidence that the calculated density of reference objects within the field of view but outside the body were correct, or could be used to correct in vivo values appropriately. ${ }^{1617}$ The present findings extend and support these previous observations.

Comparing our estimates of lung density in man with previous work is not easy for two reasons: other workers have used various degrees of lung inflation and various exclusions of hilar tissues and bronchial and vascular trees. Furthermore, most previous computed tomography estimates of lung density in man have been made close to functional residual capacity ("quiet breathing") or after an unstated degree of "full" inspiration" 1618 and inspiratory chest radiographs are usually taken at an imprecise level close to total lung capacity. Wegener et al, ${ }^{19}$ like us, ${ }^{1-38}$ preferred to use a maximum inspiration because it was more reproducible; but they do not state how this was achieved. Robinson and $\mathrm{Kreel}^{14}$ found an inverse and roughly linear relationship between lung radiodensity and lung inflation, but did not comment on the fact that, over the volume range from total lung capacity to residual volume, this association should be clearly curvilinear. Measurements of lung density have also been made with positron emission tomography ${ }^{20}$ and differences between radiographic and gas dilution lung volumes. ${ }^{121}$ The former measurements were made in the supine posture during quiet breathing and showed mean lung density to be 0.29 (SD $0.008) \mathrm{g} / \mathrm{cm}^{3}$, including the vascular component. The latter measurements were made in the erect posture and gave a lung tissue volume of 0.103 and 0.19 $(0.03) \mathrm{ml}$ tissue per $\mathrm{ml}$ (tissue and gas) at total lung capacity and functional residual capacity respectively.

We chose to compare our estimates of lung density in vivo with the morphometric data of Weibel, ${ }^{11}$ who provides sufficient information to allow estimation of the likely weight of that part of the lung seen by the computed tomography scanning routine. His study was limited to a single adult human lung obtained at necropsy. It had a total lung capacity of 6.4 litres and a total tissue volume of $1000 \mathrm{ml}$. This volume included $174 \mathrm{ml}$ of blood filled vessels, which we considered would have been sufficiently dense to be excluded by the organ identification subroutine used in this study - suggesting an expected radiodensity of "lung" tissue at total lung capacity of $(1000-174) /(6400+$ $1000-174)=0 \cdot 114$. This value should be compared 
with the mean of $0.126(0.0173)$ recorded here. The $10 \%$ excess can be attributed to the observed reductions in total lung capacity, noted in figure 5 , which are partly due to the subject's supine posture. ${ }^{9}$

We were surprised by the closeness of the estimates of tissue volume between inspiration and expiration, since they might be expected to differ. This study, however, included only intrapulmonary vessels of fairly small calibre (that is, $<5 \mathrm{~mm}$ ) by our chosen density limits.

There are several implications of the present study. Since the density range at full inspiration in normal lungs is narrow, such supine computed tomography scans can be used to identify areas of poor inflation or excess tissue volume on a slightly firmer quantitative basis than hitherto. Similarly, since the density range at full expiration, though wider, is still quite narrow, expiratory films can be used to identify areas of defective emptying or tissue loss, also on a slightly firmer quantitative basis than previously. In addition, a sequence of scans provides a map of regional ventilation and show tissue content with a little more precision than before. Changes in these variables with time might prove useful in the monitoring and management of oedema, inflammation, airway obstruction, and fibrosis. In addition, conceivably some extension of the dye dilution studies described by Reiser ${ }^{22}$ could lead to measurements of local vascular volumes and thus the separation of vascular from non-vascular tissue volumes.

We particularly wish to acknowledge the generous support and advice of Dr Basil Strickland (director of radiology); Mrs Wendy Jordan (superintendent radiographer of the computed tomography unit); Dr Bernard Fromson, who tidied up the later stages of our computer programming; and Mrs Julie Anagnostou, who typed the manuscript.

\section{References}

1 Pierce RJ, Brown DJ, Holmes M, Cumming G, Denison DM. The estimation of lung volumes from chest radiographs using shape information. Thorax 1979;34:726-34.

2 Rodenstein DO, Sopwith TA, Stanescu DC, Denison DM. Evaluation of the radiological method for measurement of total lung volume. Bull Eur Physiopathol Respir 1985;21:521-525.

3 Bush A, Denison DM. The use of different magnification factors to calculate radiological lung volumes. Thorax 1986;41:158-9.

4 Breiman RS, Beck JW, Koroblein M, et al. Volume determinations using computerised tomography. AJR 1982;138:329-33.

5 Dohring W. Quantitative analyses of regional pulmonary ventilation using Compton densitometry and computed tomography. Prog Resp Res 1979;11:48-75.

6 Brenner DE, Whitley NO, Houk TL, Aisner J, Wiernik P, Whitley J. Volume determinations in computed tomography. JAMA 1982;9:1299-302.

7 Cotes JE. Lung function: assessment and application in $\overrightarrow{0}$ medicine. 3rd ed. Oxford: Blackwell Scientific Publications, 1975.

8 Pierce RJ, Brown DJ, Denison DM. Radiographic, scintigraphic and gas-dilution estimates of individual lung $\vec{x}$ and lobar volumes in man. Thorax 1980;35:777-80.

9 Allen SJ, Hunt B, Green M. Fall in vital capacity with posture $\mathrm{Br} J$ Dis Chest 1985;79:267-71.

10 Svanberg L. Influence of posture on the lung volumes, $\mathrm{N}$ ventilation and circulation in normals; a spirometric - 은 bronchospirometric investigation. Scand J Clin Lab Invest 1957;9(suppl 25):1-195.

11 Weibel ER. The pathway for oxygen. Cambridge, Mass: Harvard University Press, 1984:281,289.

12 Huang HK, Wu SC. The evaluation of mass densities of the human body in vivo from CT scans. Comput Biol $\vec{\omega}$ Med 1976;6:337-43.

13 Hedlund LW, Vock P, Effman EL. Computed tomography of the lung densitometric studies. Radiol Clin $N$ Am 1983;21:775-88.

14 Mull RT. Mass estimates by computed tomography: physical density from CT numbers. $A J R$ 1984;143: 1101-4.

15 Hedlund L, Friedman E, Bates M, et al. A comparison of $\overrightarrow{\vec{A}}$ lung density measured gravimetrically and by computed tomography. Invest Radiol 1982;17:511.

16 Robinson PJ, Kreel L. Pulmonary tissue attenuation with computed tomography: comparison of inspiration and expiration scans. $J$ Comput Assist Tomogr 1979;3:740-8.

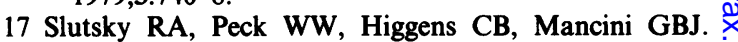
Pulmonary density distribution in experimental and $O$ clinical cardiogenic pulmonary edema evaluated by computed transmission tomography. Am Heart $J$ 1984;108:401-7.

18 Rosenblum LJ, Mauceri RA, Wallenstein DE, et al. Density patterns in the normal lung as determined by computed tomography. Radiology 1980;137:409-16.

19 Wegener OH, Koeppe P, Oeser H. Measurement of lung density by computed tomography. J Comput Assist $\mathrm{N}$ Tomogr 1978;2:1251-6.

20 Rhodes CG, Wollmer Per, Fazio Ferrucio, Jones Terry. Quantitative measurements of regional extravascular $\omega$ lung density using position emission and transmission $\sigma$ tomography. J Comput Assist Tomogr 1981;5:783-91.

21 Armstrong JD. Gluck EH, Crapo RO, Jones Hazel A, $\frac{C}{\overparen{C}}$ Hughes JMB. Lung tissue volume estimated by simultaneous radiographic and helium dilution methods. Thorax 1982;37:676-9.

22 Reiser UJ. Study of bolus geometry after intravenous contrast medium injection: dynamic and quantitative $\varrho$ measurements (chronogram) using an $x$-ray CT 으 device. J Comput Assist Tomogr 1984;8:251-62. 